\title{
New Method for Carotenoid Extraction and Analysis by HPLC-DAD-MS/MS in Freeze-Dried Citrus and Mango Pulps
}

\author{
Fabiane C. Petry* and Adriana Z. Mercadante \\ Departamento de Ciência de Alimentos, Faculdade de Engenharia de Alimentos, \\ Universidade Estadual de Campinas, 13083-862 Campinas-SP, Brazil
}

\begin{abstract}
Carotenoid analysis in citrus is still a challenge due to their complex carotenoid profile and matrix acidity, which can promote isomerization and epoxide-furanoid rearrangements of these compounds. A new method for carotenoid extraction from freeze-dried citrus was developed. Extraction was carried out by magnetic stirring using ethyl acetate and methanol as solvents and $\mathrm{Na}_{2} \mathrm{CO}_{3}$ to neutralize organic acids. Liquid-liquid partition was achieved by centrifugation. Carotenoid quantification was accomplished by both UV-Vis and high-performance liquid chromatography-diode array detection (HPLC-DAD). Method repeatability (2.9 to $8.5 \%$ ) and recovery ( 82 to $88 \%$ ) were similar to reported values for procedures including all the carotenoid analysis steps. In 'Valencia' orange pulp, xanthophylls accounted for $98 \%$ of the total carotenoid content and the predominant carotenoids were (9Z)-violaxanthin, (all-E)-lutein and (9Z)-antheraxanthin. This method was further applied for carotenoid analysis in freeze-dried 'Tommy Atkins' mango pulp. The developed method is precise, accurate, fast and able to maintain epoxy-carotenoids stability during analysis.
\end{abstract}

Keywords: chromatography, epoxy-carotenoids, epoxy-furanoid rearrangement, identification, quantification

\section{Introduction}

Carotenoids are responsible for the attractive yellow to red colors of pulp from most orange varieties. Besides color, these compounds promote health benefits, such as reduction of the risk of developing cancer, cardiovascular disorders, age related macular degeneration and cataract formation, due to regular consumption of fruits and vegetables rich in carotenoids. ${ }^{1}$

Brazil is the leader in orange (Citrus sinensis) juice production and exportation..$^{2,3}$ Moreover, orange juice consumption among Brazilians raised about $41 \%$ from 2003 to $2015 ;^{3}$ therefore, this product is a good contributor to the intake of carotenoids by the Brazilian population and also in other countries.

Orange (Citrus sinensis) is characterized by one of the most complex carotenoid profile among fruits, owning the greatest number of carotenoids already reported for any fruit. ${ }^{4,5}$ Orange pulp is rich in xanthophylls (carotenoids containing oxygen molecule(s) in the structure), more

*e-mail: fabi.cpetry@gmail.com specifically in hydroxylated epoxy-carotenoids such as violaxanthin and antheraxanthin. ${ }^{6}$

Carotenoid analysis usually comprises several steps, including sampling, extraction, partition, saponification (depending on the purpose), chromatographic analysis, identification and quantification. ${ }^{6}$ Carotenoid analysis needs to be carried out avoiding as much as possible the exposure to light, oxygen and acid; but in citrus, it is even more difficult compared to other food matrices because of the inherent matrix acidity. The presence of organic acids (e.g. citric and ascorbic) is able to promote $E / Z$ isomerization and epoxide-furanoid rearrangements of carotenoids during analysis, which could lead to misinformation about the actual carotenoid composition. In the particular case of citrus, the epoxide-furanoid rearrangement stands out as an important analytical problem in the characterization of the carotenoid composition because of the considerable amount of epoxy-carotenoids in oranges. ${ }^{6}$

Most studies concerning orange carotenoids are carried out in the juice; however, carotenoids retained in the juice vesicle membrane can be lost during juice processing, especially when a filtration step is applied. ${ }^{7}$ Therefore, the analysis of the whole pulp, including juice vesicles, 
is necessary when quantification of the actual carotenoid composition of orange pulp is required. Moreover, freezedrying fruits is an usual approach in laboratories, enabling posterior analysis of such samples.

Chloroform or acetone, or mixtures containing one of these solvents, are usually applied for carotenoid extraction from freeze-dried citrus pulp. ${ }^{8-12}$ However, both acetone and chloroform should be avoided in citrus carotenoid analysis. The presence of traces of acetone can lead to artifact formation by aldol condensation during the saponification step, since aldehydic and ketonic carotenoids may be present in this matrix. ${ }^{6}$ Moreover, chloroform should be avoided whenever possible because of its inherent toxicity.

Mango possesses a simple and well-established carotenoid composition, also constituted mainly by epoxycarotenoids, i.e. (all-E)-violaxanthin and (9Z)-violaxanthin, besides (all- $E$ )- $\beta$-carotene. ${ }^{13}$ Mango is one of the most important tropical fruit produced worldwide, along with pineapples, papaya and avocado, ${ }^{14}$ and therefore was chosen to further evaluate the developed method.

Considering all the information above, the objective was to develop and validate a new fast methodology for extraction and quantitative analysis of carotenoids by highperformance liquid chromatography-diode array detection (HPLC-DAD) of freeze-dried orange and mango pulps.

\section{Experimental}

\section{Chemicals}

Methyl tert-butyl ether (MTBE) and methanol (MeOH), both of chromatographic grade, were obtained from Tedia (Fairfield, OH, USA) and J.T. Baker (Phillipsburg, NJ, USA), respectively. Ultrapure water was obtained from the Millipore system (Billerica, MA, USA). Standards of (all-E)-lutein (purity: 92\%), (all-E)-zeaxanthin (purity: 93\%), (all-E)- $\beta$-cryptoxanthin (purity: 98\%), (all-E)- $\alpha$-carotene (purity: $92 \%$ ) and (all-E)- $\beta$-carotene (purity: 97\%) were donated by DSM Nutritional Products (Basel, Switzerland). Reagents and solvents of analytical grade were purchased from Synth (São Paulo, Brazil). For HPLC analysis, samples and solvents were filtered using, respectively, membranes of 0.22 and $0.45 \mu \mathrm{m}$, both from Millipore.

\section{Samples}

Orange (Citrus sinensis) cv. 'Valencia', both green and full-ripe (50 fruits from each ripening stage), grown in the city of Bofete $\left(23^{\circ} 5^{\prime} 54^{\prime}\right.$ ' S, $48^{\circ} 15^{\prime} 32^{\prime}$ ' W, São Paulo, Brazil), were provided by the Centro APTA Citros
Sylvio Moreira from Agronomic Institute of Campinas (IAC). Oranges in the green ripening stage were used in the recovery assays for method validation. Mango $(5 \mathrm{~kg})$ (Mangifera indica L. cv. 'Tommy Atkins') was purchased in a local market in Campinas city, Brazil.

Fruits were washed, manually peeled and after seed removal, the pulp was homogeneized taking care to maintain juice vesicles as intact as possible in citrus samples. The pulp was immediately frozen in liquid nitrogen. Frozen pulp was freeze-dried at $-60{ }^{\circ} \mathrm{C}$ below $40 \mu \mathrm{Hg}$ (Liobrás K105, São Paulo, Brazil) until constant weight. Freeze-dried pulp was ground into powder using a domestic multiprocessor, homogenized, vacuum packaged (Jumbo Plus, Selovac, São Paulo, Brazil) in polyethylene bags and stored in dark at $-80{ }^{\circ} \mathrm{C}$ for further analysis.

\section{Method development}

\section{Extraction}

Table 1 summarizes the procedures used for carotenoid extraction from freeze-dried orange pulp. Since there is no reference methodology for carotenoid analysis in citrus, the extraction described by de Rosso and Mercadante, ${ }^{15}$ which was already applied for several fruits matrices, was chosen as reference. Briefly, this method consists in exhaustively extract carotenoids from fruits with acetone by maceration using mortar and pestle. Since acetone should be avoided in citrus carotenoid analysis, we used ethyl acetate (EtOAc) and methanol $(\mathrm{MeOH})$ instead. These solvents were chosen considering their relative polarities, EtOAc presents low polarity (0.228), almost twice less polar than acetone (0.355), and $\mathrm{MeOH}$ has high polarity $(0.762):{ }^{16}$ therefore, using these solvents, a large range of polarity is comprised. Additionally, as our matrix is dry, there is no requirement for a water-soluble solvent such as acetone.

Results from maceration with mortar and pestle were compared with our proposed extraction by magnetic stirring (Marconi MA470). For both extraction techniques (maceration and magnetic stirring) the efficiency of using a mixture of EtOAc:MeOH (1:1, v/v) was compared with the efficiency of using each solvent in separated extraction steps, since exhaustive carotenoid removal from fruit matrix usually comprises more than one extraction step. The number of extractions necessary to achieve exhaustive removal of carotenoids from the orange pulp was monitored by visual color in the resultant extract. All of the five extraction procedures started by weighting $1.00 \mathrm{~g}$ of the freeze-dried orange pulp into an Erlenmeyer, followed by the addition of an equal amount of $\mathrm{Na}_{2} \mathrm{CO}_{3}$ to neutralize the acids naturally present in the matrix (Table 1). One further assay without adding the neutralizing agent was 
Table 1. Procedures evaluated for carotenoid extraction from freeze-dried orange pulp

\begin{tabular}{|c|c|c|c|c|}
\hline Procedure & Extraction & Solvent & Number of extraction & Solvent volume / $\mathrm{mL}$ \\
\hline A & maceration with mortar and pestle ( $1 \mathrm{~min})$ & $\begin{array}{l}\text { EtOAc: } \mathrm{MeOH} \\
\quad(1: 1, \mathrm{v} / \mathrm{v})\end{array}$ & 7 & $\begin{array}{c}20 \mathrm{~mL} \text { (first extraction), } \\
15 \mathrm{~mL} \text { (further extractions) } \\
\text { total: } 110 \mathrm{~mL}\end{array}$ \\
\hline B & maceration with mortar and pestle $(1 \mathrm{~min})$ & $\begin{array}{l}\text { EtOAc } \\
\mathrm{MeOH}\end{array}$ & $\begin{array}{l}5 \\
2\end{array}$ & $\begin{array}{c}20 \mathrm{~mL} \text { (first extraction), } \\
15 \mathrm{~mL} \text { (further extractions) } \\
\text { total: } 110 \mathrm{~mL}\end{array}$ \\
\hline $\mathrm{C}$ & magnetic stirring (5 min) & $\begin{array}{c}\text { EtOAc: } \mathrm{MeOH} \\
\quad(1: 1, \mathrm{v} / \mathrm{v})\end{array}$ & 4 & $\begin{array}{c}50 \mathrm{~mL} \text { (first extraction), } \\
30 \mathrm{~mL} \text { (further extractions) } \\
\text { total: } 140 \mathrm{~mL}\end{array}$ \\
\hline $\mathrm{D}$ & magnetic stirring (5 min) & $\begin{array}{c}\text { EtOAc: } \mathrm{MeOH}(1: 1, \mathrm{v} / \mathrm{v}) \\
\mathrm{MeOH}\end{array}$ & $\begin{array}{l}3 \\
1\end{array}$ & $\begin{array}{c}50 \mathrm{~mL} \text { (first extraction), } \\
30 \mathrm{~mL} \text { (further extractions) } \\
\text { total: } 140 \mathrm{~mL}\end{array}$ \\
\hline $\mathrm{E}$ & magnetic stirring (5 min) & $\begin{array}{l}\text { EtOAc } \\
\mathrm{MeOH}\end{array}$ & $\begin{array}{l}2 \\
2\end{array}$ & $\begin{array}{c}50 \mathrm{~mL} \text { (first extraction), } \\
30 \mathrm{~mL} \text { (further extractions) } \\
\text { total: } 140 \mathrm{~mL}\end{array}$ \\
\hline
\end{tabular}

carried out, using procedure E. All the carotenoid extraction experiments were conducted in triplicate. The results were evaluated by total carotenoid quantification (UV-Vis spectrophotometry).

\section{Liquid-liquid partition}

After extraction, liquid-liquid partition was carried out in a separatory funnel, i.e., the carotenoids from the combined resultant extracts of each procedure (Table 1, A-E) were transferred to diethyl ether:petroleum ether $(1: 1, \mathrm{v} / \mathrm{v})$ and washed several times with distilled water. ${ }^{15} \mathrm{In}$ order to make the partition step faster, a new procedure was evaluated, i.e., the carotenoid extract obtained by magnetic stirring (approximately $140 \mathrm{~mL}$ of extract) was combined with $100 \mathrm{~mL}$ of diethyl ether:petroleum ether $(1: 1, \mathrm{v} / \mathrm{v})$, and $150 \mathrm{~mL}$ of $10 \% \mathrm{NaCl}(\mathrm{m} / \mathrm{v})$ aqueous solution and centrifuged at $16900 \times \mathrm{g}$ for $10 \mathrm{~min}$ at $20^{\circ} \mathrm{C}$ (centrifuge Hitachi-Himac CR21).

After each partition procedure (separatory funnel or centrifugation), the organic layer containing the carotenoids was kept and remaining water traces were removed by the addition of anhydrous $\mathrm{Na}_{2} \mathrm{SO}_{4}$. Afterwards, extracts were concentrated until dryness in a rotary evaporator $\left(\mathrm{T}<35^{\circ} \mathrm{C}\right)$ and the residual solvent was removed under nitrogen flux. Dry extracts were stored at $-36{ }^{\circ} \mathrm{C}$ under nitrogen atmosphere until analysis.

\section{Total carotenoid quantification by UV-Vis}

Total carotenoid quantification by UV-Vis spectrophotometry was carried out to compare the performance of the different carotenoid extraction and liquid-liquid partition procedures. Dry extracts were suspended in a known volume of ethanol and the absorption spectrum was obtained in a diode array spectrophotometer (Agilent 8453). The total carotenoid content was calculated by using the absorbance at $436 \mathrm{~nm}$ and the specific extinction coefficient of the major carotenoid [(all-E)-violaxanthin: $\left.\left.\mathrm{E}_{\mathrm{lcm}}^{1 \%}=2550\right)\right] \cdot{ }^{17}$

New method for carotenoid extraction and liquid-liquid transference of freeze-dried orange pulp

Freeze-dried orange pulp (1.00 g) was weighted into an Erlenmeyer, followed by addition of an equal amount of $\mathrm{Na}_{2} \mathrm{CO}_{3}$. For the first extraction, $50 \mathrm{~mL}$ of EtOAc was added to the Erlenmeyer, which was covered with a stopper and submitted to magnetic stirring for $5 \mathrm{~min}$ at room temperature. The Erlenmeyer content was filtered through qualitative filter paper (thickness: $0.16 \mathrm{~mm}$, filtration speed: $20-25$ s, ash content: $0.1 \%$, particle retention: 4-12 $\mu \mathrm{m}$, UNIFIL, Alvorada, Brazil) under vacuum. The solid residue retained on the filter was transferred to the same Erlenmeyer and this process was repeated with $30 \mathrm{~mL}$ of EtOAc. Two further extractions were carried out with $30 \mathrm{~mL}$ of $\mathrm{MeOH}$ each. Carotenoid extracts (approximately $140 \mathrm{~mL}$ of extract) were combined with $100 \mathrm{~mL}$ of diethyl ether:petroleum ether $(1: 1, \mathrm{v} / \mathrm{v})$ and $150 \mathrm{~mL}$ of $10 \% \mathrm{NaCl}$ aqueous solution $(\mathrm{m} / \mathrm{v})$ and centrifuged $(16900 \times \mathrm{g}$ for $10 \mathrm{~min}$ at $20^{\circ} \mathrm{C}$ ). The upper-phase containing carotenoids was recovered.

\section{Saponification}

Extracts analyzed by HPLC-DAD-MS/MS (high-performance liquid chromatography-diode array 
detection-tandem mass spectrometry) were previously saponified. For this purpose, the dried extracts were solubilized in petroleum ether:diethyl ether $(1: 1, \mathrm{v} / \mathrm{v})$ and saponified overnight in the dark at room temperature with an equal volume of $10 \%$ methanolic $\mathrm{KOH} \cdot{ }^{15}$ The alkali was removed by washing the extract with distilled water in a separatory funnel, and the solvent evaporated in a rotary evaporator $\left(\mathrm{T}<30^{\circ} \mathrm{C}\right)$. The dry extract was stored at $-36^{\circ} \mathrm{C}$ under nitrogen atmosphere, in the dark, until analysis.

\section{HPLC-DAD-MS/MS analysis}

HPLC analysis was carried out in a Shimadzu equipment (Kyoto, Japan), possessing a quaternary pump (LC-20AD), online degasser (DGU-20A5), and a Rheodyne injection valve (Rohnert Park, CA, USA) with a $20 \mu \mathrm{L}$ loop. The system was connected in series with a diode array detector (DAD) (Shimadzu, SPD-M20A) and a mass spectrometer, with an ion-trap mass analyzer and atmospheric pressure chemical ionization source (APCI), from Bruker Daltonics, model AmaZon speed ETD (Bremem, Germany). Carotenoids were separated on a C30 YMC column C30 YMC ( $5 \mu \mathrm{m}, 250 \times 4.6 \mathrm{~mm}$, Waters, DE, USA), using a linear gradient of $\mathrm{MeOH}$ and MTBE, from 95:5 to 70:30 in $30 \mathrm{~min}$ followed by 50:50 in $20 \mathrm{~min} .{ }^{18}$ Flow rate was set at $0.9 \mathrm{~mL} \mathrm{~min}^{-1}$, the UV-Vis spectra were obtained between 250 and $600 \mathrm{~nm}$, and chromatograms were processed at $450 \mathrm{~nm}$. The column temperature was set at $29^{\circ} \mathrm{C}$.

MS parameters were the same described by Chisté and Mercadante, ${ }^{18}$ except that the dry gas flow was set at $5 \mathrm{~L} \mathrm{~min}^{-1}$ and nebulizer set at $60 \mathrm{psi}$. The mass spectra were acquired with scan range from $\mathrm{m} / \mathrm{z}, 100$ to 650 . Carotenoids were identified according to the following combined information: elution order on C30 column, co-chromatography with authentic standards, UV-Vis spectrum $\left(\lambda_{\max }\right.$, spectral fine structure (III/II, \%) and cis peak intensity $\left(\mathrm{A}_{\mathrm{B}} / \mathrm{A}_{\mathrm{II}}, \%\right)$ ) and mass spectrum compared with data available in literature. ${ }^{15,19,20}$ Quantification was carried out using external analytical curves of (all-E)-lutein, (all-E)-zeaxanthin, (all-E)- $\beta$-cryptoxanthin, (all-E)- $\alpha$ carotene, (all-E)- $\beta$-carotene, with five concentration levels; $Z$ isomers were quantified using the curve of the corresponding (all-E)-isomer; (all-E)-violaxanthin, (all-E)-antheraxanthin, $($ all- $E$ )-luteoxanthin and their $(Z)$-isomers were quantified using the curve of lutein; and (all-E)-zeinoxanthin using the curve of (all-E)- $\beta$-cryptoxanthin.

\section{Method validation}

The extraction procedure that provided the highest carotenoid content in orange was validated according to the following parameters: linearity, limits of detection and quantification (LOD and LOQ), accuracy (recovery) and precision. $^{21}$

Linearity was evaluated by checking the detector response in area units (in triplicate) to different carotenoid concentrations through a linear regression. ${ }^{21}$ At least five-point analytical curves of (all-E)-lutein, (all-E)-zeaxanthin, (all-E)- $\beta$-cryptoxanthin, (all-E)- $\alpha$-carotene and (all-E)- $\beta$-carotene standards were constructed. LODs and LOQs were determined using parameters of the analytical curve. ${ }^{21}$

Recovery was determined by spiking samples of orange cv. 'Valencia', in the green ripening stage, with known amounts of (all- $E$ )-lutein, (all- $E$ )- $\beta$-cryptoxanthin and (all-E)- $\beta$-carotene standards prior to extraction, in three addition levels for each carotenoid. The spiking levels were $5.16,10.3$ and $14.72 \mu \mathrm{g} \mathrm{g}^{-1}$ of lutein, 1.89 , 3.76 and $7.54 \mu \mathrm{g} \mathrm{g}^{-1}$ of $\beta$-cryptoxanthin, and $0.61,1.23$ and $3.08 \mu \mathrm{g} \mathrm{g} \mathrm{g}^{-1}$ of $\beta$-carotene. The spiked samples were extracted using the developed method, saponified and analyzed by HPLC-DAD-MS, in triplicate. Repeatability (within-day precision) was determined and expressed as relative standard deviation (\% RSD). ${ }^{21}$

\section{Statistical analysis}

Statistical analysis was obtained in Origin 8.0 and Statistica 7.0 softwares. Results were evaluated by Student's $t$-test for two independent samples and for three or more samples, one way analysis of variance (ANOVA) was applied and significant differences among means were detected by Tukey's test $(p<0.05)$. Regression curves were checked for homoscedasticity and linearity through residual plots and $F$-test.

\section{Results and Discussion}

Evaluation of pre-chromatographic steps for carotenoid analysis: extraction and liquid-liquid partition

Results of total carotenoid content (UV-Vis spectrophotometry) obtained for the different extraction procedures are shown in Table 2. The highest total carotenoid content was observed in procedure $\mathrm{E}$ (magnetic stirring), although it was not significantly different from procedure B (maceration with mortar and pestle) $(p<0.05)$. In fact, carotenoids from freeze-dried orange pulp were satisfactory extracted just by stirring the sample and solvent during an adequate time, and therefore an extra abrasion obtained by maceration with mortar and pestle was not required. Moreover, maceration extraction (procedure B) 
involved more steps, with higher possibility of carotenoid losses, which explains the slightly lower carotenoid content obtained by this procedure when compared to procedure $\mathrm{E}$. Higher number of extraction steps was necessary to obtain a colorless extract in the maceration procedure: seven compared to four in magnetic stirring, probably because abrasion was able to extract also other colored compounds, such as flavanones, present in orange pulp..$^{22}$ Furthermore, the results from Table 2 also show that individual extraction steps for each solvent (EtOAc and $\mathrm{MeOH}$ ) were 6 to $10 \%$ more effective in extracting carotenoids, most likely because they comprise a higher range of polarities in comparison to their mixture (EtOAc:MeOH, 1:1). Other advantage of the magnetic stirring procedure is that it was $60 \%$ faster than maceration, since simultaneous triplicate extractions could be performed in around $45 \mathrm{~min}$, whereas at least $2 \mathrm{~h}$ were required if the same triplicate extractions were carried out by maceration. Regarding solvent consumption, both extraction procedures were similar (approximately $140 \mathrm{~mL}$ for magnetic stirring and $110 \mathrm{~mL}$ for maceration). Taking into account the obtained results, procedure $\mathrm{E}$ was chosen for the subsequent analysis.

As oranges are naturally acid matrices, favoring the occurrence of 5,6-epoxy to 5,8-furanoids rearrangement during the analysis, ${ }^{6}$ extractions with and without the addition of a neutralizing agent $\left(\mathrm{Na}_{2} \mathrm{CO}_{3}\right)$ were carried out. Figure 1a shows changes in the UV-Vis absorption spectra shape of the carotenoid extracts related to replicates 1 and 2 when extraction was done without a neutralizing agent. In this case, the absorbance at ca. $443 \mathrm{~nm}$ and ca. $465 \mathrm{~nm}$ decreased, concomitantly to the increase in absorbance at ca. $420 \mathrm{~nm}$. The observed hypsochromic shift $(23 \mathrm{~nm})$ is typical of an epoxy-furanoid rearrangement, which is catalyzed by organic acids. As can be observed in Figure 1b, the addition of $\mathrm{Na}_{2} \mathrm{CO}_{3}$ was effective to avoid such rearrangement during analysis, since no alterations in the UV-Vis absorption spectra were evidenced within the replicates.

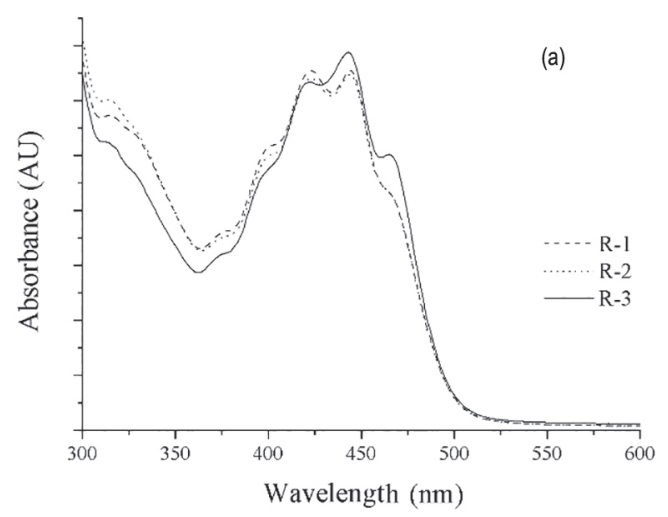

Table 2. Total carotenoid contents, expressed as (all-E)-violaxanthin, in non-saponified extracts from freeze-dried orange cv. 'Valencia' pulp, obtained through different extraction procedures

\begin{tabular}{lcc}
\hline Procedure & Total carotenoid content ${ }^{\mathrm{a}} /\left(\mu \mathrm{g} \mathrm{g}^{-1}\right)$ & $\mathrm{RSD}^{\mathrm{b}} / \%$ \\
\hline $\mathrm{A}$ & $124.68 \pm 3.32^{\mathrm{B}}$ & 2.66 \\
$\mathrm{~B}$ & $137.58 \pm 2.09^{\mathrm{AB}}$ & 1.52 \\
$\mathrm{C}$ & $132.45 \pm 7.32^{\mathrm{AB}}$ & 5.52 \\
$\mathrm{D}$ & $133.25 \pm 5.50^{\mathrm{AB}}$ & 4.20 \\
$\mathrm{E}$ & $140.45 \pm 4.96^{\mathrm{A}}$ & 3.53 \\
\hline
\end{tabular}

${ }^{a}$ Mean and standard deviation of three replicates $(n=3)$, expressed in dry basis; 'relative standard deviation. ${ }^{\mathrm{A} B \mathrm{~B}}$ Values with different letters were significantly different (Tukey's test; $p<0.05$ ). A: 7 maceration steps, using a mixture of EtOAc:MeOH 1:1 as solvent; B: 5 maceration steps with EtOAc and 2 maceration steps with $\mathrm{MeOH} ; \mathrm{C}: 4$ extraction steps by magnetic stirring with a mixture of EtOAc:MeOH 1:1; D: 3 extraction steps by magnetic stirring with a mixture of EtOAc:MeOH 1:1 and one further extraction with $\mathrm{MeOH}$; $\mathrm{E}: 2$ extraction steps by magnetic stirring with EtOAC and 2 extraction steps with $\mathrm{MeOH}$. Further details of the extraction procedures can be found in Material and Methods section.

Carotenoid extraction from freeze-dried pulps does not require a partition step after extraction, as usually carried out for fresh samples extracted with water miscible solvents, such as acetone. In the latter case, carotenoids are transferred to apolar solvents, such as petroleum ether and diethyl ether after extraction. However, in our experiments, when the fractions obtained by extractions with EtOAc and $\mathrm{MeOH}$ were pooled, a white substance precipitated, probably due to the presence of polysaccharides from the juice vesicle membrane, such as pectin and hemicellulose, which are insoluble in alcohol. ${ }^{23}$ Since this precipitate was water-soluble, in this case, a liquid-liquid partition step was required as a cleanup step to remove such polysaccharides. Thus, a simpler and faster partition procedure was evaluated and compared to the tradition partition in separatory funnel, and the results are shown in Table 3. The replacement of the liquid-liquid partition in separatory funnel by the proposed centrifugation step increased both total carotenoid content

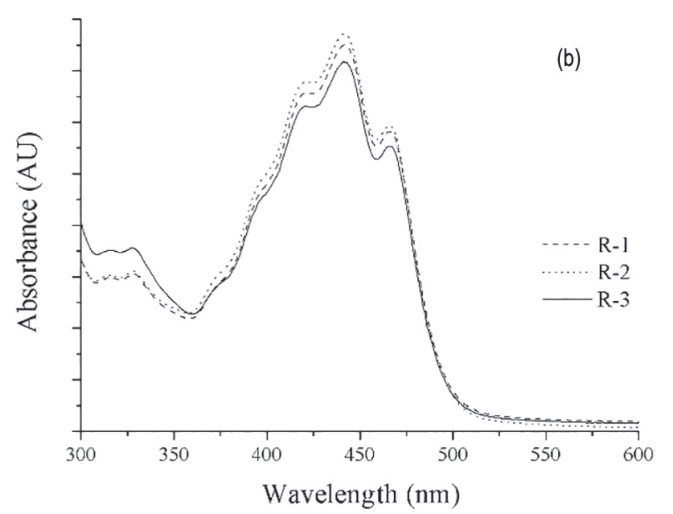

Figure 1. UV-Vis spectra of carotenoid extracts from Valencia orange pulp (a) without addition of $\mathrm{Na}_{2} \mathrm{CO}_{3}$ previously to extraction and (b) with the addition of $\mathrm{Na}_{2} \mathrm{CO}_{3}$ previously to extraction. $\mathrm{R}$ means replicate of extraction. 
and repeatability, due to the lower number of required analysis steps in the alternative procedure. Moreover, partition by centrifugation is up to 30 times faster and saves at least six liters of distilled water per triplicate when compared to the traditional liquid-liquid carotenoid procedure.

Table 3. Total carotenoid contents, expressed as (all-E)-violaxanthin, from freeze-dried pulp of orange cv. 'Valencia', after liquid-liquid partition carried out in separatory funnel and by centrifugation

\begin{tabular}{lcc}
\hline Liquid-liquid partition & $\begin{array}{c}\text { Total carotenoid } \\
\text { content }^{\mathrm{a}} /\left(\mu \mathrm{g} \mathrm{g}^{-1}\right)\end{array}$ & $\mathrm{RSD}^{\mathrm{b}} / \%$ \\
\hline Separatory funnel & $140.45 \pm 4.96^{\mathrm{B}}$ & 3.53 \\
Centrifuge & $156.81 \pm 1.84^{\mathrm{A}}$ & 1.18 \\
\hline
\end{tabular}

aalues are mean and standard deviation of three replicates $(n=3)$, expressed in dry basis; ${ }^{b}$ relative standard deviation. ${ }^{\mathrm{A}, \mathrm{B}}$ Values with different letters were significantly different ( $t$-test for independent samples, $p<0.05)$.

The aqueous phase resultant from centrifuge partition presented some yellowish color, probably related to the presence of flavanones extracted with $\mathrm{MeOH}$, since the recorded UV-Vis absorption spectra of the aqueous phase showed no evidences of carotenoid losses. This fact is expected since $\mathrm{MeOH}^{24,25}$ as well as mixtures of $\mathrm{MeOH}$ and water ${ }^{18,26}$ are commonly applied for extraction of phenolic compounds.

\section{Method validation}

Table 4 shows the results from linearity evaluation, linear range, LOD and LOQ. Results from recovery and repeatability are shown in Table 5. For all the analytical curves, the linear regression was significant $(p<0.05)$ in the evaluated concentration ranges, which is also corroborated by the high values of the determination coefficient $\left(r^{2} \geq 0.993\right)$. Moreover, the residual plots showed an aleatory distribution, indicating that the data followed a Gaussian distribution. The calculated LOD $\left(0.38-0.91 \mu \mathrm{g} \mathrm{mL}^{-1}\right)$ and LOQ (1.15-2.77 $\mu \mathrm{g} \mathrm{mL}-1)$ were similar to those of $\beta$-carotene and lycopene (LOD: $0.127-0.511 \mu \mathrm{g} \mathrm{mL} \mathrm{m}^{-1}$ and LOQ: 0.511-1.55 $\mu \mathrm{g} \mathrm{mL}^{-1}$ ) reported by Rajendran et al. ${ }^{27}$ These authors also calculated the limits using parameters of the analytical curves, but another solvent system consisting of $\mathrm{MeOH}$ and dichloromethane was applied for carotenoid separation in HPLC. ${ }^{27}$ On the other hand, LOD and LOQ values reported by Chisté and Mercadante ${ }^{18}$ were lower (LOD: $0.1 \mu \mathrm{g} \mathrm{mL} \mathrm{L}^{-1}$ and LOQ: $0.5 \mu \mathrm{g} \mathrm{mL} \mathrm{m}^{-1}$ ) for a set of carotenoids (i.e., (9Z)-neoxanthin, (all-E)-violaxanthin, (all-E)-antheraxanthin, (all-E)-lutein, (all-E)-zeaxanthin, and (all-E)- $\beta$-carotene) using the same equipment and similar mobile phases and gradient elution as applied in the present work. In the latter work, authors also calculated the limits from the parameters of analytical curves; however, different concentration ranges of carotenoids were evaluated, which could have influenced the calculated limits.

The method accuracy was determined by recovery of (all-E)-lutein, (all-E)- $\beta$-cryptoxanthin and (all-E)- $\beta$-carotene standards spiked at three concentration levels in samples of unripe orange cv. 'Valencia'. Recovery values varied from 85 to $88 \%$ for (all-E)-lutein, 83 to $86 \%$ for (all- $E$ )- $\beta$-cryptoxanthin and 83 to $85 \%$ for (all-E)- $\beta$-carotene (Table 6). These values revealed approximately $15 \%$ of carotenoid losses during the complete analytical procedure, including extraction, saponification and HPLC analysis. Recent studies ${ }^{28-30}$ related to carotenoid recoveries including all analysis steps reported similar results. Stinco et al. ${ }^{28}$ reported recoveries of around $82 \%$ for (all- $E$ )- $\beta$-carotene when saponification step was included. In the same study, when samples were analyzed without alkaline hydrolysis the recovery values ranged from 92 to $107 \% .{ }^{28}$ Delpino-Rius et al. ${ }^{29}$ reported recoveries of $82 \%$ for (9Z)-neoxanthin and $75 \%$ for (all- $E$ )-violaxanthin in samples spiked prior to extraction and followed by saponification. Inbaraj et al. ${ }^{30}$ reported recoveries of zeaxanthin, $\beta$-cryptoxanthin and $\beta$-carotene of 92,92 and $87 \%$, respectively, without saponification, while with saponification, recoveries dropped to 83,74 and $74 \%$, respectively. In order to allow peak quantification, saponification was applied in the present study because

Table 4. Parameters of method validation

\begin{tabular}{|c|c|c|c|c|c|}
\hline Carotenoid & Linear range $/\left(\mu \mathrm{g} \mathrm{mL}^{-1}\right)$ & Linear regression $^{\mathrm{b}}$ & $r^{2}$ & $\mathrm{LOD} /\left(\mu \mathrm{g} \mathrm{mL} L^{-1}\right)$ & $\mathrm{LOQ} /\left(\mu \mathrm{g} \mathrm{mL}^{-1}\right)$ \\
\hline (all-E)-Lutein & $1.53-24.43$ & $y=373591.5 x-210030.2$ & 0.998 & 0.51 & 1.54 \\
\hline (all-E)-Zeaxanthin & $1.46-21.64$ & $y=430716.1 x-83713.1$ & 0.997 & 0.48 & 1.45 \\
\hline (all-E)- $\beta$-Cryptoxanthin & $2.52-26.23$ & $y=416456.7 x-80162.1$ & 0.995 & 0.83 & 2.52 \\
\hline (all-E)- $\alpha$-Carotene & $0.99-8.44$ & $y=375635.2 x+93477.8$ & 0.995 & 0.38 & 1.15 \\
\hline (all-E)- $\beta$-Carotene & $2.77-25.71$ & $y=443449.9 x+47112.9$ & 0.993 & 0.91 & 2.77 \\
\hline
\end{tabular}

${ }^{a}$ Curves constructed in triplicate; ${ }^{b} y$ is the DAD response in area units (mAU) and $\mathrm{x}$ is the carotenoid concentration $\left(\mu \mathrm{g} \mathrm{mL}^{-1}\right)$. $\mathrm{r}^{2}$ : determination coefficient; LOD: limit of detection; LOQ: limit of quantification. 
Table 5. Recovery and repeatability of the developed method

\begin{tabular}{|c|c|c|c|c|c|c|}
\hline \multirow[t]{2}{*}{ Carotenoid } & \multirow[t]{2}{*}{$\begin{array}{l}\text { Concentration in the } \\
\text { matrix }^{\mathrm{a}, \mathrm{b}} /\left(\mu \mathrm{g} \mathrm{g}^{-1}\right)\end{array}$} & \multicolumn{2}{|c|}{ Spiked amount / $\left(\mu \mathrm{g} \mathrm{g}^{-1}\right)$} & \multirow{2}{*}{$\begin{array}{c}\begin{array}{c}\text { Experimental } \\
\text { amount }^{\mathrm{a}} /\left(\mu \mathrm{g} \mathrm{g}^{-1}\right)\end{array} \\
9.91 \pm 0.22\end{array}$} & \multirow{2}{*}{$\begin{array}{c}\text { Recovery / \% } \\
85.1 \pm 4.2\end{array}$} & \multirow{2}{*}{$\begin{array}{c}\begin{array}{c}\text { Repeatability } \\
\text { (\% RSD) }\end{array} \\
4.9\end{array}$} \\
\hline & & level 1 & 5.16 & & & \\
\hline \multirow[t]{3}{*}{ (all-E)-Lutein } & $5.52 \pm 0.58$ & level 2 & 10.30 & $14.26 \pm 0.31$ & $84.9 \pm 3.1$ & 3.6 \\
\hline & & level 3 & 14.72 & $18.53 \pm 0.44$ & $88.4 \pm 3.0$ & 3.4 \\
\hline & & level 1 & 1.88 & $2.94 \pm 0.12$ & $82.9 \pm 6.4$ & 7.8 \\
\hline \multirow[t]{3}{*}{ (all-E)- $\beta$-Cryptoxanthin } & $1.38 \pm 0.02$ & level 2 & 3.76 & $4.61 \pm 0.15$ & $85.9 \pm 3.9$ & 4.5 \\
\hline & & level 3 & 7.54 & $7.67 \pm 0.31$ & $83.4 \pm 4.1$ & 4.9 \\
\hline & & level 1 & 0.64 & $0.90 \pm 0.03$ & $83.4 \pm 4.7$ & 5.6 \\
\hline \multirow[t]{2}{*}{ (all-E)- $\beta$-Carotene } & $0.37 \pm 0.02$ & level 2 & 1.26 & $1.44 \pm 0.04$ & $85.0 \pm 3.4$ & 4.0 \\
\hline & & level 3 & 3.08 & $2.93 \pm 0.09$ & $83.1 \pm 2.8$ & 3.4 \\
\hline
\end{tabular}

aMeans and standard deviations of three replicates; ' recovery assays were carried out using freeze-dried pulp of unripe orange cv. "Valencia".

106 carotenoids were identified by LC-DAD-MS/MS in non-saponified extract from orange cv. 'Valencia', with several co-elution even though different mobile phases and gradients have been applied. Therefore, a reliable quantification of carotenoids present in the non-saponified extract of orange was impaired. ${ }^{5}$

Precision of analysis (extraction, saponification and chromatographic quantitation) was evaluated by means of intra-day repeatability, and results are expressed as RSD (\%) in Table 5. Values of RSD ranged from 3.4\% for (all-E)-lutein and (all-E)- $\beta$-carotene (level 3) to 7.8\% for (all-E)- $\beta$-cryptoxanthin, confirming the repeatability of the developed method. These values are considerably lower than previous studies on repeatability of carotenoids considering all the analytical steps, in which reported values ranged from 14.5 to $26.4 \% .^{28}$

Identification of carotenoids in the saponified extract from pulp of orange cv. 'Valencia' and mango cv. 'Tommy Atkins'

Using the method described above, 19 carotenoids were separated by HPLC in the saponified extract from

Table 6. Chromatographic, UV-Vis, mass spectrometry characteristics and contents of carotenoids, obtained by HPLC-DAD-MS/MS, in orange cv. 'Valencia' and mango cv. 'Tommy Atkins'

\begin{tabular}{|c|c|c|c|c|c|c|c|c|c|}
\hline \multirow[t]{2}{*}{ Peak $^{\mathrm{a}}$} & \multirow[t]{2}{*}{ Carotenoid } & \multicolumn{2}{|c|}{$\begin{array}{l}\text { Concentration of freeze } \\
\text { dried pulp }^{\mathrm{b}} /\left(\mu \mathrm{g} \mathrm{g}^{-1}\right)\end{array}$} & \multirow[t]{2}{*}{$t_{R}{ }^{c} / \min$} & \multirow[t]{2}{*}{$\lambda_{\max }{ }^{\mathrm{d}} / \mathrm{nm}$} & \multirow[t]{2}{*}{ III/II / \% } & \multirow[t]{2}{*}{$\mathrm{A}_{\mathrm{B}} / \mathrm{A}_{\mathrm{II}} / \%$} & \multirow[t]{2}{*}[\mathrm{M}+\mathrm{H}]{$^{+}(m / z)$} & \multirow[t]{2}{*}{ Fragment ions $(\mathrm{m} / \mathrm{z})$} \\
\hline & & Orange & Mango & & & & & & \\
\hline 1 & mixture & $1.8 \pm 0.1$ & $\mathrm{nd}^{\mathrm{e}}$ & $6.2-6.3$ & $\begin{array}{c}395,421,441, \\
465\end{array}$ & $\mathrm{nc}^{\mathrm{f}}$ & $\mathrm{nd}^{\mathrm{e}}$ & $\mathrm{nd}^{\mathrm{e}}$ & $\mathrm{nd}^{\mathrm{e}}$ \\
\hline 2 & (di-Z)-violaxanthin & $3.9 \pm 0.2$ & $\mathrm{nd}^{\mathrm{e}}$ & 6.6 & $\begin{array}{c}\text { 328, } 409,430, \\
455\end{array}$ & 15 & 30 & 601 & $\mathrm{nd}^{\mathrm{e}}$ \\
\hline 3 & (9Z)-neoxanthin & $\mathrm{nd}^{\mathrm{e}}$ & $15.2 \pm 1.5$ & 6.7 & $\begin{array}{c}\text { 330, } 415,440, \\
469\end{array}$ & 84 & 24 & 601 & $\begin{array}{c}583[\mathrm{M}+\mathrm{H}-18]^{+}, \\
565[\mathrm{M}+\mathrm{H}-18-18]^{+}, \\
509[\mathrm{M}+\mathrm{H}-92]^{+}, \\
491[\mathrm{M}+\mathrm{H}-92-18]^{+}, 221\end{array}$ \\
\hline 4 & (di-Z)-violaxanthin & $4.1 \pm 0.1$ & $n d^{e}$ & $6.8-6.9$ & $\begin{array}{c}328,408,429, \\
456\end{array}$ & 35 & 32 & 601 & $\mathrm{nd}^{\mathrm{e}}$ \\
\hline 5 & (all-E)-violaxanthin & $8.8 \pm 0.5$ & $66.9 \pm 1.1$ & $7.3-7.4$ & $414,438,467$ & 78 & 0 & 601 & $\begin{array}{c}583[\mathrm{M}+\mathrm{H}-18]^{+}, \\
565[\mathrm{M}+\mathrm{H}-18-18]^{+}, \\
547[\mathrm{M}+\mathrm{H}-18-18-18]^{+}, \\
509[\mathrm{M}+\mathrm{H}-92]^{+}, \\
491[\mathrm{M}+\mathrm{H}-92-18]^{+}, 221\end{array}$ \\
\hline 6 & (all-E)-luteoxanthin & $5.1 \pm 0.2$ & $4.7 \pm 0.2$ & 8.5 & $400,421,447$ & 93 & 0 & 601 & $\begin{array}{c}583[\mathrm{M}+\mathrm{H}-18]^{+}, \\
565[\mathrm{M}+\mathrm{H}-18-18]^{+}, \\
547[\mathrm{M}+\mathrm{H}-18-18-18]^{+}, \\
509[\mathrm{M}+\mathrm{H}-92]^{+}, \\
491[\mathrm{M}+\mathrm{H}-92-18]^{+}, 221\end{array}$ \\
\hline 7 & not identified & $2.6 \pm 0.01$ & $\mathrm{nd}^{\mathrm{e}}$ & 9.1 & $\begin{array}{c}\text { 329, } 402,424, \\
445\end{array}$ & 19 & 27 & 601 & $\begin{array}{c}583[\mathrm{M}+\mathrm{H}-18]^{+}, \\
565[\mathrm{M}+\mathrm{H}-18-18]^{+}, \\
509[\mathrm{M}+\mathrm{H}-92]^{+}, \\
491[\mathrm{M}+\mathrm{H}-92-18]^{+}, 221\end{array}$ \\
\hline
\end{tabular}


Table 6. Chromatographic, UV-Vis, mass spectrometry characteristics and contents of carotenoids, obtained by HPLC-DAD-MS/MS, in orange cv. 'Valencia' and mango cv. 'Tommy Atkins' (cont.)

\begin{tabular}{|c|c|c|c|c|c|c|c|c|}
\hline \multirow[t]{2}{*}{ Peak $^{a}$} & \multirow[t]{2}{*}{ Carotenoid } & \multicolumn{2}{|c|}{$\begin{array}{l}\text { Concentration of freeze } \\
\text { dried pulp } /\left(\mu \mathrm{g} \mathrm{g}^{-1}\right)\end{array}$} & \multirow{2}{*}{$\mathrm{t}_{\mathrm{R}}^{\mathrm{c}} / \min$} & \multirow[t]{2}{*}{$\lambda_{\max }{ }^{\mathrm{d}} / \mathrm{nm}$} & \multirow[t]{2}{*}{ III/II / \% } & \multirow{2}{*}{$\mathrm{A}_{\mathrm{B}} / \mathrm{A}_{\mathrm{II}} / \%$} & \multirow{2}{*}[\mathrm{M}+\mathrm{H}]{$^{+}(m / z)$} \\
\hline & & Orange & Mango & & & & & \\
\hline
\end{tabular}

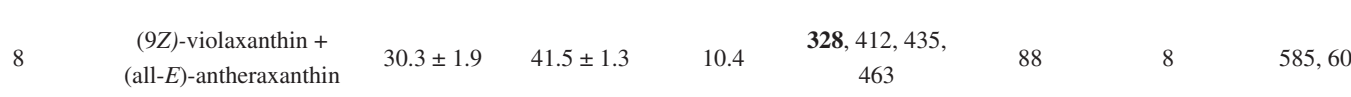

\begin{tabular}{|c|c|c|c|c|c|c|c|c|c|}
\hline 9 & $(9 Z)$ or $\left(9^{\prime} Z\right)$-luteoxanthin & $2.3 \pm 0.2$ & $\mathrm{nd}^{\mathrm{e}}$ & 10.8 & $\begin{array}{c}\text { 310, } 396,417 \\
442\end{array}$ & 98 & 13 & 601 & $\mathrm{nd}^{\mathrm{e}}$ \\
\hline 10 & $(9 Z)$ or $\left(9^{\prime} Z\right.$ )-luteoxanthin & $5.5 \pm 0.3$ & $\mathrm{nd}^{\mathrm{e}}$ & 11.4 & $\begin{array}{c}\mathbf{3 1 0}, 395,417 \\
443\end{array}$ & 94 & 10 & 601 & $\begin{array}{c}583[\mathrm{M}+\mathrm{H}-18]^{+}, \\
565[\mathrm{M}+\mathrm{H}-18-18]^{+}, \\
509[\mathrm{M}+\mathrm{H}-92]^{+}, \\
491[\mathrm{M}+\mathrm{H}-92-18]^{+}, 221\end{array}$ \\
\hline 11 & mutatoxanthin epimer & $2.1 \pm 0.1$ & $\mathrm{nd}^{\mathrm{e}}$ & $12.0-12.1$ & $400,428,449$ & 70 & 0 & 585 & $\begin{array}{c}567[\mathrm{M}+\mathrm{H}-18]^{+}, \\
549[\mathrm{M}+\mathrm{H}-18-18]^{+}, \\
493[\mathrm{M}+\mathrm{H}-92]^{+}, 221 \\
\end{array}$ \\
\hline 12 & (all-E)-lutein & $11.5 \pm 0.7$ & $\mathrm{nd}^{\mathrm{e}}$ & 12.4 & $415,444,472$ & 50 & 0 & 569 & $\begin{array}{c}551[\mathrm{M}+\mathrm{H}-18]^{+, g} \\
533[\mathrm{M}+\mathrm{H}-18-18]^{+}, \\
477[\mathrm{M}+\mathrm{H}-92]^{+} \\
\end{array}$ \\
\hline 13 & mutatoxanthin epimer & $1.3 \pm 0.1$ & $\mathrm{nd}^{\mathrm{e}}$ & 13.0 & $402,427,451$ & 63 & 0 & 585 & $\begin{array}{c}567[\mathrm{M}+\mathrm{H}-18]^{+}, \\
549[\mathrm{M}+\mathrm{H}-18-18]^{+}, \\
493[\mathrm{M}+\mathrm{H}-92]^{+}, 221 \\
\end{array}$ \\
\hline 14 & (all-E)-zeaxanthin & $7.9 \pm 0.5$ & $\mathrm{nd}^{\mathrm{e}}$ & 14.7 & $413,450,476$ & 29 & 0 & 569 & $\begin{array}{c}551[\mathrm{M}+\mathrm{H}-18]^{+}, \\
533[\mathrm{M}+\mathrm{H}-18-18]^{+}, \\
495[\mathrm{M}+\mathrm{H}-56-18]^{+}, \\
476[\mathrm{M}-92]^{+}\end{array}$ \\
\hline 15 & (9Z)-antheraxanthin & $10.6 \pm 0.7$ & $\mathrm{nd}^{\mathrm{e}}$ & 15.7 & $\begin{array}{c}\mathbf{3 3 0}, 410,440 \\
468\end{array}$ & 60 & 9 & 585 & $\begin{array}{c}567[\mathrm{M}+\mathrm{H}-18]^{+}, \\
549[\mathrm{M}+\mathrm{H}-18-18]^{+}, \\
493[\mathrm{M}+\mathrm{H}-92]^{+}, \\
475[\mathrm{M}+\mathrm{H}-92-18]^{+}, 221\end{array}$ \\
\hline 16 & $\begin{array}{l}(15 Z) \text { or (13Z)- } \\
\text { zeinoxanthin + phytoene }\end{array}$ & $1.0 \pm 0.02$ & $\mathrm{nd}^{\mathrm{e}}$ & 17.5 & $\begin{array}{c}\mathbf{3 3 0}, 412,443 \\
467\end{array}$ & 16 & 51 & 553,545 & $\begin{array}{c}\text { [553]: } 535[\mathrm{M}+\mathrm{H}-18]^{+}, \\
461[\mathrm{M}+\mathrm{H}-92]^{+} ; \\
{[545]: 489[\mathrm{M}+\mathrm{H}-56]^{+}} \\
\end{array}$ \\
\hline 17 & (all-E)-zeinoxanthin & $2.4 \pm 0.1$ & $\mathrm{nd}^{\mathrm{e}}$ & $19.0-19.1$ & $414,445,472$ & 56 & 0 & 553 & $\begin{array}{c}535[\mathrm{M}+\mathrm{H}-18]^{+}, \\
460[\mathrm{M}-92]^{+}\end{array}$ \\
\hline 18 & (all-E)- $\beta$-cryptoxanthin & $4.2 \pm 0.3$ & $0.3 \pm 0.04$ & 22.5 & $415,450,477$ & 26 & 0 & 553 & $\begin{array}{l}535[\mathrm{M}+\mathrm{H}-18]^{+}, \\
461[\mathrm{M}-\mathrm{H}-92]^{+}\end{array}$ \\
\hline 19 & (13Z)- $\beta$-carotene & $\mathrm{nd}^{\mathrm{e}}$ & $3.7 \pm 0.002$ & 27.8 & $\begin{array}{c}338,422,445 \\
470 \\
\end{array}$ & 7 & 44 & 537 & $\mathrm{nd}^{\mathrm{e}}$ \\
\hline 20 & (all-E)- $\alpha$-carotene & $0.8 \pm 0.07$ & $\mathrm{nd}^{\mathrm{e}}$ & 28.1 & $410,445,472$ & 53 & 0 & 537 & $\begin{array}{c}481[\mathrm{M}+\mathrm{H}-56]^{+}, \\
444[\mathrm{M}-92]^{+}, \\
413,401,299,281 \\
\end{array}$ \\
\hline 21 & (all- $E$ )- $\beta$-carotene & $1.3 \pm 0.1$ & $43.3 \pm 0.2$ & 32.3 & $412,451,478$ & 17 & 0 & 537 & $444[\mathrm{M}-92]^{+}, 413$ \\
\hline \multirow[t]{3}{*}{22} & (9Z)- $\beta$-carotene & $\mathrm{nd}^{\mathrm{e}}$ & $3.3 \pm 0.2$ & 34.5 & $\begin{array}{c}339,421,447 \\
473\end{array}$ & 17 & 6 & 537 & $\mathrm{nd}^{\mathrm{e}}$ \\
\hline & $\begin{array}{c}\text { Total carotenoids of } \\
\text { freeze-dried pulp / } \\
\left(\mu \mathrm{g} \mathrm{g}^{-1}\right)\end{array}$ & $107 \pm 5$ & $180 \pm 13$ & & & & & & \\
\hline & $\begin{array}{l}\text { Total carotenoids of } \\
\text { fresh pulp / }\left(\mu \mathrm{g} \mathrm{g}^{-1}\right)\end{array}$ & $14.2 \pm 0.7$ & $25.2 \pm 1.8$ & & & & & & \\
\hline
\end{tabular}

a Numbered according to the chromatograms shown in Figure 1; bmean and standard deviation of three replicates $(\mathrm{n}=3)$; ' $r e t e n t i o n$ time on the $\mathrm{C} 30$ column; ${ }^{\text {dinear gradient of }}$

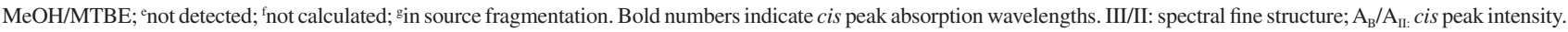

orange cv. 'Valencia' (Figure 2), and 17 were identified or tentatively identified using the combined information of elution order on C30 column, UV-Vis and MS spectra characteristics (Table 6). The characteristics of the eight peaks separated in mango cv. 'Tommy Atkins' can also be found in Table 6. Only the most relevant aspects are 

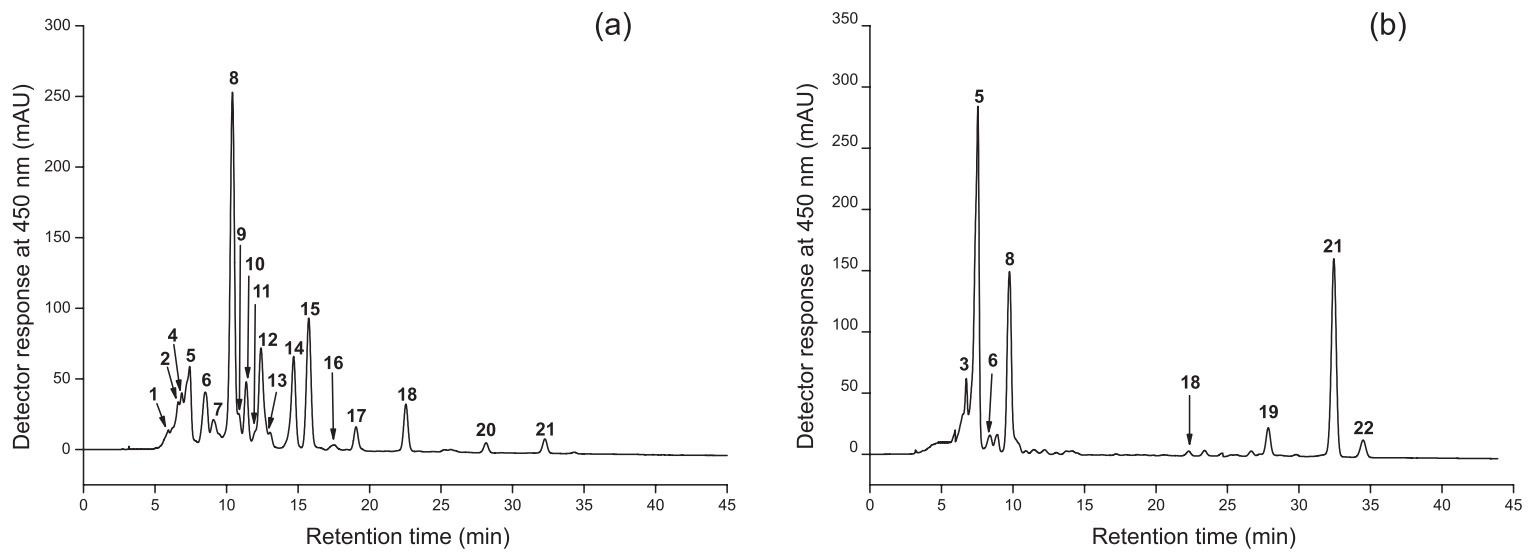

Figure 2. Chromatogram obtained by HPLC-DAD of carotenoids in orange cv. 'Valencia' (a) and in mango cv. 'Tommy Atkins' (b). Chromatographic conditions: see text. Peak characterization is given in Table 6.

commented below as detailed description of carotenoid identification of saponified extracts of carotenoids from fruits can be found in the literature. $15,18,20,31,32$

The major carotenoid (peak 8) of orange cv. 'Valencia' was assigned as a mixture of (all-E)-antheraxanthin and (9Z)-violaxanthin since both protonated molecules $\left([\mathrm{M}+\mathrm{H}]^{+}\right)$were detected, respectively, at $m / 2,585$ and 601 at the same retention time $\left(t_{R}\right)$. Interestingly, the UV-Vis spectrum of (9Z)-violaxanthin was not influenced by coelution with (all-E)-antheraxanthin, probably because the amount of the violaxanthin isomer is much higher when compared to that of antheraxanhin. These carotenoids are very difficult to separate, even in a C30 column with gradient elution since both compounds also coeluted under different chromatographic conditions. ${ }^{5,33}$ One of the major carotenoids in pulp of mango cv. 'Tommy Atkins' is also (9Z)-violaxanthin, but in this fruit the MS spectrum of (all-E)-antheraxanthin was not detected.

Peaks 2 and 4 were tentatively identified as (di-Z)-violaxanthin isomers. Elution of these isomers immediately before the (all-E)-violaxanthin peak, the $[\mathrm{M}+\mathrm{H}]^{+}$at $m / z 601$, and the hypsochromic shifts of 8-9 nm compared to that of the (all- $E$ )-isomerand the $c$ is peakintensities $\left(A_{B} / A_{I I}=30-32 \%\right)$ supported this conclusion. However, it is not possible to assign the position of the $Z$ double bounds with the available information. Moreover, (mono-Z)-isomers that usually elute before the corresponding (all-E)-isomer on C30 column, (15Z)- or (13Z)-isomers, show smaller hypsochromic shifts (2-6 nm) and higher intensities of cis peak than those presented here, and they were not observed in the present study. These (di-Z)-violaxanthin isomers were only detected in orange pulp, and their occurrence in orange juice was previously reported by Meléndez-Martínez et al. ${ }^{34}$

Peaks 9 and 10, detected in orange, were tentatively identified as (9Z)- and/or (9' Z)-isomers of luteoxanthin, considering the hypsochromic shift of $4 \mathrm{~nm}$ and their elution after the correspondent (all-E)-isomer, as well as the protonated molecule at $\mathrm{m} / \mathrm{z}, 601$ and characteristic fragments of a xanthophyll with epoxide groups. Peak 6, (all-E)-luteoxanthin, was found in orange and mango. Peaks 11 and 13 showed identical absorption maxima and MS spectra, and were assigned as 9 and 9' $Z$ epimers of mutatoxanthin. These epimers are known to elute immediately before and after (all-E)-lutein on C30 column. ${ }^{33,35}$ As mutatoxanthin is a structural isomer of antheraxanthin with one furanoid group at position 5,8instead of the 5,6-epoxide group of antheraxanthin, the MS data of both carotenoids showed similar features, and supported its identification. Mutatoxanthin epimers were only detected in orange.

(9Z)-Neoxanthin (peak 3) was detected in mango, supported by previous findings, ${ }^{13}$ but was not detected in orange. In fact, neoxanthin does not occur in relevant levels in orange juice. ${ }^{36}$ Neoxanthin possesses identical spectral features than those of the violaxanthin, and their differentiation is only possible considering the earlier elution of neoxanthin.

(all-E)-Lutein (peak 12) and (all-E)-zeaxanthin (peak 14) have the same chemical formula $\left(\mathrm{C}_{40} \mathrm{H}_{56} \mathrm{O}_{2}\right)$ and, therefore, identical $[\mathrm{M}+\mathrm{H}]^{+}$, but with different fragment intensities. In lutein, the $[\mathrm{M}+\mathrm{H}]^{+}$at $m / z, 569$ is less intense than the fragment at $m / z 551[\mathrm{M}+\mathrm{H}-18]^{+}$, which indicates that one hydroxyl group is allylic to the double bond, facilitating its elimination. ${ }^{15}$ The opposite occurs in the zeaxanthin MS spectrum, $[\mathrm{M}+\mathrm{H}]^{+}$more intense than $[\mathrm{M}+\mathrm{H}-18]^{+}$. This fact also affects the UV-Vis features and elution of these carotenoids, allowing their unequivocally identification. Peak 17 was assigned as (all-E)-zeinoxanthin. Although $\alpha$-cryptoxanthin possesses identical UV-Vis spectrum and similar chromatographic behavior, differentiation is easily carried out by mass spectrometry, as previously 
described. ${ }^{15,37}$ Lutein, zeaxanthin and zeinoxanthin were only detected in orange pulp.

The UV-Vis absorption spectra of peak 1 indicated coelution of different carotenoids. However, the MS spectrum showed only $[\mathrm{M}+\mathrm{H}]^{+}$at $m / z, 601$ and fragments at $\mathrm{m} / \mathrm{z}, 583$ and 565, indicating two consecutive losses of water (18 u). Considering these facts, all carotenoids coeluting in this retention time are probably di-hydroxylated xanthophylls with two epoxy/furanoid groups. Moreover, the fragment at $\mathrm{m} / \mathrm{z} 221$ confirms the presence of an epoxy group on a hydroxylated end-group. Therefore, this peak likely contains a mixture of geometrical isomers of violaxanthin or luteoxanthin.

Because of the low intensity of the DAD signal obtained for peak 7 , some spectral features were not accurately detected. Therefore, this minor peak remained without identification, but several considerations can be made considering its $[\mathrm{M}+\mathrm{H}]^{+}$at $m / z 601$ and fragments at $\mathrm{m} / \mathrm{z} 587$ and 565 indicating one $(18 \mathrm{u})$ and two $(36 \mathrm{u})$ neutral losses of water molecules, respectively, as well as a fragment at $m / z, 221$. Thus, this peak is most possibly a di-hydroxylated di-epoxy carotenoid.

Xanthophylls are predominant in Valencia orange pulp, accounting for around $98 \%$ of the total carotenoid content. The major xanthophylls found were (9Z)-violaxanthin, (all-E)-lutein and (9Z)-antheraxanthin (Table 2), corresponding to, respectively, 28, 11 and $10 \%$ of the total carotenoid content. Considerable amounts of (all-E)-violaxanthin, (all-E)-zeaxanthin, (9Z or 9'Z)-luteoxanthin, (all-E)-luteoxanthin and (all-E)- $\beta$-cryptoxanthin were also found. These results are in agreement with previous studies also conducted with Valencia orange juice, which reported $(Z)$-violaxanthin and antheraxanthin as the major carotenoids. ${ }^{38,39}$ In a recent study, violaxanthin, antheraxanthin, and their geometrical isomers, as well as luteoxanthin and mutatoxanthin were found as the major carotenoids in ultrafrozen juice from Valencia late orange. ${ }^{40}$

The developed method was also applied to freeze-dried mango, and concerning its carotenoid composition, (all-E)-violaxanthin was the major compound (37\%), followed by (all- $E$ )- $\beta$-carotene (24\%) and (9Z)-violaxanthin $(23 \%)$. Other minor compounds, such as $\beta$-carotene cis-isomers and neoxanthin, were also detected (Table 6). Mango is known by owning high carotenoid content, which could range from 12.5 to $55 \mu \mathrm{g} \mathrm{g}^{-1}$ of fresh weight depending on the cultivar and ripening stage. ${ }^{41}$ Our results are in agreement with previous reports on mango carotenoid composition. ${ }^{41-43}$

Moreover, the developed method was also applied to extract carotenoids from orange cv. 'Pera' and tangor cv. 'Murcott', but since the non-saponified extract was characterized in that work, a different mobile phase and gradient elution was applied to achieve separation of carotenoid esters and these compounds were not quantified. ${ }^{5}$

\section{Conclusions}

In summary, a new method for carotenoid extraction from freeze-dried orange pulp was successfully developed and validated, briefly consisting in exhaustively extract carotenoids from the dry pulp by sequential steps of magnetic stirring with ethyl acetate, followed by methanol, with the previous addition of $\mathrm{Na}_{2} \mathrm{CO}_{3}$ to neutralize organic acids. The extraction is followed by a liquid-liquid partition to an ethereal phase in a centrifugation step. This method was also applied for another freeze-dried matrix, mango. Repeatability (3.4 to $7.8 \%$ ) and recovery ( 82 to $88 \%$ ) values were in the range of those reported for procedures including all the analysis steps (extraction, saponification and chromatographic separation). Carotenoid composition of orange cv. 'Valencia' and mango cv. 'Tommy Atkins' was determined using the new methodology. Xanthophylls were responsible for $98 \%$ of the total carotenoid content in the saponified extract of orange, and the predominant carotenoids were (9Z)-violaxanthin, followed by (all-E)-lutein and (9Z)-antheraxanthin. In mango, (all-E)-violaxanthin, (all-E)- $\beta$-carotene and (9Z)-violaxanthin were the major carotenoids. Results indicate that the developed method is appropriate for carotenoid analysis in orange and mango freeze-dried pulps, and considering analysis triplicate it is around 4 fold faster compared to the maceration with mortar and pestle, commonly applied for several fruits.

\section{Acknowledgments}

The authors thank to São Paulo Research Foundation (FAPESP) (Grants No. 2013/09804-5 and No. 2013/07914-8).

\section{References}

1. Saini, R. K.; Nile, S. H.; Park, S. W.; Food Res. Int. 2015, 76, 735

2. http://www.brasil.gov.br/economia-e-emprego/2016/02/brasilnegocia-ampliacao-das-exportacoes-de-suco-de-laranja-para-achina, accessed in June 2017.

3. http://www.citrusbr.com/nocampo/?id=311907, accessed in February 2017.

4. Gross, J.; Gabai, M.; Ufshitz, A.; J. Food Sci. 1971, 36, 466.

5. Petry, F. C.; Mercadante, A. Z.; J. Agric. Food Chem. 2016, 64, 8207. 
6. Meléndez-Martínez, A. J.; Vicario, I. M.; Heredia, F. J.; J. Food Compos. Anal. 2007, 20, 638.

7. Rodrigo, M. J.; Cilla, A.; Barberá, R.; Zacarías, L.; Food Funct. 2015, 6, 1950.

8. Rodrigo, M. J.; Marcos, J. F.; Alférez, F.; Mallent, M. D.; Zacarías, L.; J. Exp. Bot. 2003, 54, 727.

9. Vanamala, J.; Cobb, G.; Turner, N.; Lupton, J. R.; Yoo, K. S.; Pike, L. M.; Patil, B. S.; J. Agric. Food Chem. 2005, 53, 3980.

10. Wang, Y. C.; Chuang, Y. C.; Ku, Y. H.; Food Chem. 2007, 102, 1163.

11. Xu, C. J.; Fraser, P. D.; Wang, W. J.; Bramley, P. M.; J. Agric. Food Chem. 2006, 54, 5474.

12. Goulas, V.; Manganaris, G. A.; Food Chem. 2012, 131, 39.

13. Mercadante, A. Z.; Rodriguez-Amaya, D.; Britton, G.; J. Agric. Food Chem. 1997, 45, 120.

14. http://www.fao.org/docrep/006/y5143e/y5143e1a.htm, accessed in February 2017.

15. de Rosso, V. V.; Mercadante, A. Z.; J. Agric. Food Chem. 2007, 55,5062

16. Reichardt, C.; Solvents and Solvent Effects in Organic Chemistry, $3^{\text {rd }}$ ed.; Wiley-VCH Publishers: Berlin, 2003.

17. Davies, B. H.; Chemistry and Biochemistry of Plant Pigments, vol 2.; Academic Press: London, 1976.

18. Chisté, R. C.; Mercadante, A. Z.; J. Agric. Food Chem. 2012, 60,5884

19. Britton, G.; Liaaen-Jensen, S.; Pfander, H.; Carotenoids: Handbook; Birkhäuser Verlag: Basel, 2004.

20. Van Breemen, R. B.; Dong, L.; Pajkovic, N. D.; Int. J. Mass Spectrom. 2012, 312, 163.

21. Ribani, M.; Bottoli, C. B. G.; Collins, C. H.; Jardim, I. C. S. F.; Melo, L. F. C.; Quim. Nova 2004, 27, 771.

22. Peterson, J. J.; Dwyer, J. T.; Beecher, G. R.; Bhagwat, S. A.; Gebhardt, S. E.; Haytowitz, D. B.; Holden, J. M.; J. Food Compos. Anal. 2006, 19, S66.

23. Sinclair, W. B.; Crandall, P. R.; Bot. Gaz. 1951, 113, 106.

24. Caristi, C.; Bellocco, E.; Gargiulli, C.; Toscano, G.; Leuzzi, U.; Food Chem. 2006, 95, 431.

25. Xi, W.; Fanga, B.; Zhao, Q.; Jiao, B.; Zhou, Z.; Food Chem. 2014, 161, 230.
26. Swatsitang, P.; Tucker, G.; Robards, K.; Jardine, D.; Anal. Chim. Acta 2000, 417, 231.

27. Rajendran, V.; Pu, Y. S.; Chen, B. H.; J. Chromatogr. B 2005, $824,99$.

28. Stinco, C. M.; Benítez-González, A. M.; Hernanz, D.; Vicario, I. M.; Meléndez-Martínez, A. J.; J. Chromatogr. A 2014, 1370, 162.

29. Delpino-Rius, A.; Eras, J.; Marsol-Vall, A.; Vilaró, F.; Balcells, M.; Canela-Garayoa, R.; J. Chromatogr. A 2014, 1331, 90.

30. Inbaraj, B. S.; Lu, H.; Hung, C. F.; Wu, W. B.; Lin, C. L.; Chen, B. H.; J. Pharm. Biomed. Anal. 2008, 47, 812.

31. Mariutti, L. R. B.; Rodrigues, E.; Mercadante, A. Z.; J. Food Compos. Anal. 2013, 31, 155.

32. Rodrigues, E.; Mariutti, L. R. B.; Mercadante, A. Z.; J. Agric. Food Chem. 2013, 61, 3022.

33. Meléndez-Martínez, A. J.; Vicario, I. M.; Heredia, F. J.; J. Agric. Food Chem. 2007, 55, 1347.

34. Meléndez-Martínez, A. J.; Vicario, I. M.; Heredia, F. J.; Food Chem. 2007, 104, 169.

35. Meléndez-Martínez, A. J.; Britton, G.; Vicario, I. M.; Heredia, F. J.; J. Agric. Food Chem. 2005, 53, 9369.

36. Meléndez-Martínez, A. J.; Britton, G.; Vicario, I. M.; Heredia, F. J.; Food Chem. 2008, 107, 49.

37. Schlatterer, J.; Breithaupt, D. E.; J. Agric. Food Chem. 2005, 53,6355 .

38. Lee, H. S.; Coates, G. A.; LWT - Food Sci. Technol. 2003, 36, 153.

39. Curl, A. L.; Bailey, G. F.; Food Technol. 1959, 13, 394.

40. Stinco, C. M.; Fernández-Vázquez, R.; Escudero-Gilete, M. L.; Heredia, F. J.; Meléndez-Martínez, A. J.; Vicario, I. M.; J. Agric. Food Chem. 2012, 60, 1447.

41. Mercadante, A. Z.; Rodriguez-Amaya, D. B.; J. Agric. Food Chem. 1998, 46, 128.

42. Pott, I.; Breithaupt, D. E.; Carle, R.; Phytochemistry 2003, 64, 825.

43. Ornelas-Paz, J. J.; Yahia, E.; Gardea-Bejar, A.; J. Agric. Food Chem. 2007, 55, 6628. 